\title{
Childhood Adversity and Borderline Personality Disorder: A Meta-Analysis
}

\author{
Carly Porter $^{1}$ \\ Jasper Palmier-Claus ${ }^{2,3}$ \\ Alison Branitsky ${ }^{1}$ \\ Warren Mansell ${ }^{1}$ \\ Helen Warwick ${ }^{1}$ \\ Filippo Varese ${ }^{1,4}$
}

${ }^{1}$ Division of Psychology and Mental Health, Faculty of Biology, Medicine and Health, The University of Manchester, United Kingdom.

${ }^{2}$ Spectrum Centre for Mental Health Research, Division of Health Research, Lancaster University, Lancaster, Lancashire, United Kingdom.

${ }^{3}$ Lancashire Care NHS Foundation Trust, Lancashire, United Kingdom.

${ }^{4}$ Complex Trauma and Resilience Research Unit, Greater Manchester Mental Health NHS Foundation Trust, Manchester Academic Health Science Centre, Manchester (UK)

Corresponding author: Jasper Palmier-Claus (J.Palmier-Claus@lancaster.ac.uk): Spectrum Centre, Health Research, Faculty of Health \& Medicine, Lancaster University, Lancaster, United Kingdom. 


\section{Acknowledgements}

We would like to thank Dr Samet Kose, Dr Jeong-Ho Seok, Dr Ana Hernández

Fernández, Dr Alvaro Frias Ibañez, Dr Jeremy Hall, Dr Royce Lee, Dr Areti

Spiropoulou, Dr Stefan Tschöke, Dr Katja Wingenfeld and Dr Mary Zanarini who

generously gave their time to provide additional information or data in support of this review. The are no conflicts of interest arising from this research. The NHS funded this research as part of the lead author's doctorate in clinical psychology.

\section{Data Privacy Statement}

Data sharing is not applicable to this article as no new data were created or analyzed in this study. 


\begin{abstract}
Objective: The aim of this meta-analysis was to better understand the magnitude and consistency of the association between childhood adversity and borderline personality disorder (BPD) across case-control, epidemiological and prospective cohort studies.
\end{abstract}

Method: Following the review protocol (reference: CRD42017075179), search terms pertaining to adversity and BPD, were entered into three search engines. Random effects meta-analysis synthesised the size and consistency of the effects.

Results: 97 studies compared BPD to non-clinical $(\mathrm{k}=40)$ and clinical $(\mathrm{k}=70)$ controls. Meta-analysis of case control studies indicated that individuals with BPD are 13.91 (95\% CI 11.11-17.43) times more likely to report childhood adversity than nonclinical controls. This effect was smaller when considering retrospective cohort (OR: 2.59; 95\% CI .93-7.30) and epidemiological (OR: 2.56, 95\% CI 1.24-5.30) studies. Findings were significant across adversity subtypes with emotional abuse (OR: 38.11 , 95\% CI: 25.99-55.88) and neglect (OR: 17.73, 95\% CI=13.01-24.17) demonstrating the largest effects. Individuals with BPD were 3.15 (95\% CI 2.62-3.79) times more likely to report childhood adversity than other psychiatric groups.

Conclusions: This meta-analysis corroborates theoretical proposals that exposure to adverse life experiences is associated with BPD. It highlights the importance of considering childhood adversity when treating people diagnosed with BPD. 


\section{Key words}

Borderline personality disorder, adversity, trauma, meta-analysis.

\section{Summations}

- Patients with BPD were over 13 times more likely to report childhood adversity than non-clinical controls.

- They were also more likely to report childhood adversity then other clinical populations.

- Emotional abuse and neglect were particularly elevated in BPD samples relative to controls.

\section{Limitations}

- Most studies employed retrospective assessments of childhood adversity.

- We identified only two prospective design studies in the literature.

- A risk of publication bias was identified for the majority of the analyses. However, the effects remained statistically significant even after controlling for possible publication bias. 


\section{Introduction}

Borderline personality disorder (BPD) is characterised by affect instability, identity disturbance, interpersonal difficulties and harmful behaviours. In order to meet diagnostic criteria these difficulties must be deemed stable and be having a significant impact on daily functioning $(1,2)$. BPD has been identified as the most common personality disorder in clinical populations (3), and it is associated with significant individual and societal costs (3-8). Given the severe impact of BPD, there is a considerable need to understand its risk factors to inform preventative and therapeutic interventions.

Current treatment options for BPD have demonstrated varied levels of efficacy. A recent meta-analysis reported small to moderate effects for Dialectical Behaviour Therapy (DBT) and psychodynamic therapies, whereas other psychological interventions, including cognitive behaviour therapy, have failed to demonstrate substantial treatment benefit in randomised trials (9). DBT is based on Linehan's Biosocial Theory (10), which emphasises the importance of a child's early experiences in the development of BPD. In particular, it is suggested that early emotional invalidation from caregivers limits opportunities for the child to learn how to experience and control different emotional states. Similarly, psychoanalytic theories emphasis the central role of early experiences and relationships with caregivers in the development of implicit regulation processes around emotion and motivation (11). In the light of the growing evidence indicating that exposure to childhood adversities in an influential determinant of multiple salient features of BPD (e.g. affect instability, emotion regulation difficulties, maladaptive coping strategies such as substance misuse and selfharm; (e.g. 12, 13)), there is a strong theoretical rationale for hypothesising that early adverse life experiences are central to the development of this disorder. Indeed, it has 
been suggested that many experiences of BPD may be understood as complex posttraumatic stress disorders $(14,15))$.

Childhood adversity is associated with a wide range of negative clinical outcomes in adulthood (16), including a range of severe mental health presentations including mood disorders $(7,8)$, psychosis (17) and personality disorders (18). A large number of empirical studies have explored the link between different forms of childhood adversity (e.g. emotional, physical, sexual abuse, neglect) and BPD. In addition, narrative reviews have attempted to bring clarity to this question by synthesising and evaluating findings from this growing area of research (e.g.19-22). These informative reviews have generally supported the importance of considering childhood adversity as a prominent contributor of BPD risk, but also raised queries about the specificity and consistency of the relationship across studies.

Despite the large body of research exploring the relationship between childhood adversity and BPD, meta-analytic studies in this area are sparse. A recent systematic review and meta-analysis of potential aetiological and psychopathological factors associated with youth BPD (i.e. in people age 19 or younger, 23) found that young people with BPD are more likely to report a range of childhood adversities relative to controls without BPD, including experiences of sexual and physical abuse, neglect, maladaptive parenting and parental conflict. To date, only one meta-analysis has attempted to synthesise the considerably larger corpus of research that has considered adult samples; this meta-analysis specifically focused on childhood sexual abuse and demonstrated a significant but only moderate association with BPD (24). As many studies assess a range of adverse childhood experiences, there is an urgent need for an updated and more comprehensive synthesis of this literature. 


\section{Aims of the study}

The primary objectives of this meta-analysis were:

1) To investigate whether exposure to childhood adversity is elevated in adults with a diagnosis of BPD compared to non-clinical and clinical controls (e.g. mood disorder, other personality disorders, psychosis).

2) To investigate which types of childhood adversity were most elevated in BPD samples compared to non-clinical controls.

3) To investigate whether exposure to childhood adversity is elevated in BPD compared to specific types of clinical controls. 


\section{Method}

The review was carried out in accordance with the Preferred Reporting Items for Systematic Reviews and Meta-Analyses (PRISMA) standards. The full review protocol is available on a data repository website (http://www.crd.york.ac.uk/PROSPERO/; reference: CRD42017075179).

Systematic search

Searches were conducted using three electronic databases (Medline, Embase, and PsychInfo) in September 2017 and updated in June 2019. These were restricted to articles published post 1980 (when BPD first appeared as a bona fide diagnosis in diagnostic classification systems) and those written in the English language. Search terms relating to BPD (borderline* OR personality disorder OR emotionally unstable OR cluster b) were combined with terms relating to childhood adversity (Child abuse OR physical abuse OR sexual abuse OR psychological abuse OR emotional abuse OR neglect* OR trauma* OR advers* OR maltreat* OR bully* OR bullied OR victim*OR parental loss). Where possible, appropriate MeSH terms (i.e. personality disorder in PsychInfo; borderline states in Embase) were used to further expand the database searches. The lead author screened reference lists of previous reviews to identify relevant articles missed through the database search (see supplementary table S1).

The review included studies with samples over 18 years of age with a diagnosis BPD according to the Diagnostic and Statistical Manual of Mental Disorders (DSM-III, DSM-IIIR, DSM-IV, DSM-IV-TR \& DSM-5) or International Classification of Diseases (ICD-9 or ICD-10) of Emotionally Unstable Personality Disorder according to the International Classification of Diseases system. Analyses were restricted to the diagnostic construct of BPD, rather than individual features of BPD shared with other diagnostic groups. All studies were required to have a systematic quantitative measure 
of childhood adversity defined as reporting neglect, abuse, bullying or the loss of parents before the age of 19 . In line with previous meta-analytic syntheses (17), studies that assessed childhood adversity via unsystematic or opportunistic case note reviews were excluded due to possible response bias. In order to meet eligibility, studies were also required to employ case control, prospective cohort or epidemiological designs to investigate the association between childhood adversity and BPD diagnosis. Case control studies were required to have at least one non-clinical or clinical control group.

Screening was carried out by the lead author and occurred in three stages: title level, abstract level and full text level. A second researcher screened one third of titles (85.6\% agreement) and abstracts (80.2\% agreement). In all cases, discrepancies were due to the overinclusion of reports by the primary reviewer. The whole team screened and discussed the full article level papers until consensus on eligibility was established.

Extracted data included both statistical information to estimate relevant effect sizes (e.g. counts of exposed and unexposed participants across BPD and control groups; sample sizes as well as means and standard deviation of adversity measure; precalculated effect sizes) and study relevant descriptors (e.g. year of publication, country, study design, control type, diagnostic classification system, type of adversity). The lead author extracted all of the data with a second author (either JPC or FV) checking information in the eligible papers for accuracy. In cases where the relevant information from which to calculate an effect size or determine eligibility was unavailable, the authors requested further information with the corresponding authors of the primary studies.

The Newcastle Ottawa Assessment Scale (NOAS; 25) was used to assess the methodological quality of the included studies. This scale rates potential methodological bias across three areas: selection (rated on a 0-4 scale), comparability of index (in this 
case, BPD participants) and control samples (rated on a 0-2 scale) and assessment of exposure (rated on a 0-3 scale). In order to rate comparability of samples, the NOAS requires the authors to predetermine one or two key matching variables or covariates. Age and gender were selected given evidence suggesting that BPD symptoms alleviate with age (26) and variation in BPD prevalence according to gender (27). All included studies were independently double-rated by two authors and discrepancies were discussed until consensus was reached.

To address our research questions, we conducted a series of random effect metaanalyses using Comprehensive Meta-Analysis V2 software (28). All effect sizes extracted from the primary studies were converted to Odds Ratio (OR) for these analyses. First, we synthesised studies examining whether exposure to childhood adversity is elevated in individuals with BPD compared to non-clinical samples. This was based on effects extracted from studies that exclusively focused on either single types of adversity (i.e. any type of adverse experience considered in this review) or studies which employed a summary measure of multiple childhood adversities. In studies that provided data for multiple individual types of adverse experiences, but no summary exposure score, effect sizes for specific adversities were aggregated to produce a combined effect, which was then included in the analysis. Second, we explored the effect of exposure to specific types of adversity (i.e. sexual abuse, physical abuse, emotional abuse, emotional neglect, physical neglect) on BPD. Direct contrast of these effects was not possible as we were unable to determine if participants had reported multiple forms of abuse resulting in non-independence. Third, we synthesised studies examining whether exposure to childhood adversity is elevated in individuals with BPD compared to clinical samples in general and specific psychiatric groups of interest (i.e. other personality disorders, psychotic disorders and mood disorders). We ensured no overlap between study samples within each analysis. 
Across all analyses, individual study effects were screened for potential outliers, defined as studies in which the $95 \%$ CI of the study was outside the $95 \%$ CI of the pooled effect (29). In order to explore heterogeneity across studies, the Q-test and $\mathrm{I}^{2}$ were used examine and quantify the amount of observed variance explained by true heterogeneity, rather than sampling error. Visual exploration of funnel plots and the Egger's test were used to explore publication and selection bias. In cases where publication bias was confirmed, the Duval and Tweedie Trim and Fill method was used to correct for the presence of bias and adjust the results for the effect of likely missing effects. Meta-regression was used to test the relationship between NOAS quality ratings and effect sizes. 


\section{Results}

Figure 1 shows a diagram detailing the flow of papers across each stage of screening. The searches identified 97 eligible studies, considering a combined sample size of 11,366 BPD participants, 3,732 non-clinical controls and 13,128 psychiatric controls. The vast majority of eligible studies employed a case-control design $(k=92)$. Given the small number of eligible epidemiological $(\mathrm{k}=3)$ and prospective $(\mathrm{k}=2)$ studies all of the meta-analyses conducted on the effect sizes extracted from the primary studies were stratified according to research design (i.e. no attempt was made to integrate effect sizes extracted from case-control, prospective and epidemiological studies into the same analysis).

Overall prevalence of childhood adversity in BPD samples

Forty-two studies provided relevant statistical information to estimate the weighted pooled percentage of participants reporting childhood adversity within BPD samples considered in this meta-analysis. Overall, $71.1 \%$ of BPD participants reported at least one adverse childhood experience. Analyses focusing on specific types of adversities indicated that the most common form was physical neglect $(48.9 \%)$, followed by emotional abuse (42.5\%), physical abuse (36.4\%), sexual abuse (32.1\%) and emotional neglect $(25.3 \%)$.

\section{Childhood Adversity in BPD and Non-Clinical Samples}

Supplementary Table S2 shows the characteristics of studies included in the primary analyses. Forty studies compared individuals with a diagnosis of BPD to nonclinical samples on measures of childhood adversity. 


\section{[INSERT FIGURE 1 APPROXIMATELY HERE]}

Table 1 shows the summary effects, heterogeneity statistics and publication bias statistics for all analyses comparing individuals with BPD to non-clinical controls. These analyses include both original analyses (i.e. including all eligible studies) and analyses with outliers removed. Where relevant (i.e. when publication/selection bias was evident) trim and fill corrected analyses are also presented. Considerable levels of statistical heterogeneity were observed across all analyses, as indicated by significant Q tests and substantial $\mathrm{I}^{2}$ statistics (ranging between $27.97 \%$ to $98.34 \%$ ). Furthermore, the Egger's test revealed potential publication bias across most analyses. In the subsequent sections, we describe only analyses that accounted for the influence of publication bias and/or the presence of potential influential cases (i.e. outliers), unless otherwise specified.

\section{Overall Effect of Childhood Adversity}

Figure 2 presents a forest plot of the case control studies $(k=29)$ after the removal of potential outliers (30-40). This analysis indicated that individual with BPD are 16.86 times more likely to report childhood adversity than non-clinical controls $(95 \%$ CI 13.76-20.66, $p<.001)$. Meta-regression analysis revealed that NOAS quality ratings did not affect the observed effects $(\beta=-.001, \mathrm{SE}=.05, p=.999)$.

Table 1 contains effect sizes for each stage of the analysis. After the inclusion of seven hypothetically missing studies via the Trim and Fill method, the synthesis of case control studies comparing childhood adversity in BPD and non-clinical controls 
remained robust and significant; $\mathrm{OR}=13.91,(95 \% \mathrm{CI}=11.11-17.43, p<.001)$. This indicated that individuals with BPD are over 13 times more likely to report childhood adversity than non-clinical controls. A separate synthesis conducted on two epidemiological studies showed an overall effect size of OR $=2.56(95 \%$ CI 1.24-5.30, $p=.011)$. Similarly, a separate meta-analysis of the two prospective studies showed an overall effect size of $\mathrm{OR}=2.59(95 \%$ CI $0.93-7.30, p=.070)$, which was nonsignificant. However, the effect sizes extracted from each individual study showed a significant relationship with variation in the magnitude of the effect: $\mathrm{OR}=4.99(95 \% \mathrm{CI}$ $1.83-13.5, p=.001)$ and $\mathrm{OR}=1.70(95 \% \mathrm{CI} 1.31-2.20, p<.001)$ respectively. Due to the small number of epidemiological and prospective studies available, it was not possible to conduct heterogeneity and publication bias analyses for these studies.

[INSERT FIGURE 2 APPROXIMATELY HERE]

Effect of Physical Abuse

After the removal of identified outliers $(30,32,36-37,53,56,64,68)$ and for the inclusion of seven potentially missing studies, a pooled effect of OR=7.06 (95\% CI 5.26 $-9.48, p<.001)$ was observed for physical abuse. One epidemiological study and one prospective cohort study examined the association physical abuse and BPD, indicating effects of $\mathrm{OR}=2.40(95 \% \mathrm{CI}=1.70-2.45, p<.001)$ and $\mathrm{OR}=2.09(95 \% \mathrm{CI}=1.71-2.44$, $p<.001)$ 


\section{Effect of Sexual Abuse}

After the removal of outliers $(30,36-37)$ and the inclusion of five potentially missing studies, case control studies comparing childhood sexual abuse in BPD and non-clinical controls indicated a pooled effect of $\mathrm{OR}=5.96(95 \% \mathrm{CI} 4.72-7.52, p<.001)$. Only one epidemiological study and one prospective cohort study examined sexual abuse indicating effects of $\mathrm{OR}=2.47(95 \% \mathrm{CI}=1.42-2.97, p<.001)$ and $\mathrm{OR}=1.46(95 \%$ $\mathrm{CI}=.67-3.18, p=.340)$ respectively.

\section{Effect of Emotional Abuse}

After the removal of outliers $(32,36-37,50,56-57,59,64)$ and the inclusion of two potentially missing studies, case control studies comparing levels of reported emotional abuse in BPD and non-clinical controls led to a pooled effect of $\mathrm{OR}=38.11$ $(95 \% \mathrm{CI}=25.99-55.88, p<.001)$. One epidemiological study and one prospective cohort study examined emotional abuse indicating effects of $\mathrm{OR}=2.31(95 \% \mathrm{CI}=1.87-2.86, p<$ $.001)$ and $\mathrm{OR}=4.99(95 \% \mathrm{CI}=1.83-13.55, p=.002)$.

\section{Effect of Emotional Neglect}

For emotional neglect, seven outliers were removed $(32,36-37,50,57,59,64)$ and six potentially missing studies were included. A meta-analysis of case control studies comparing childhood adversity in BPD and non-clinical controls indicated a pooled effect of $\mathrm{OR}=17.73(95 \% \mathrm{CI}=13.01-24.17, p<.001)$. 


\section{Effect of Physical Neglect}

After removal of outliers $(32,36-37,41,53,69)$ and the inclusion of four potentially missing studies, a meta-analysis of case control studies which compared BPD and non-clinical controls on measures of physical neglect led to a pooled effect of $\mathrm{OR}=6.93(95 \% \mathrm{CI}=5.23-9.20, p<.001)$

\section{[INSERT TABLE 1 APPROXIMATELY HERE]}

\section{Childhood adversity in BPD and Clinical Controls}

Supplementary Table S2 presents the characteristics of all studies included in analyses comparing BPD to clinical controls. Sixty-nine case control studies and one epidemiology study compared BPD to clinical control samples. Table 2 shows the summary effects, and heterogeneity and publication statistics, for these analyses. The Q and $\mathrm{I}^{2}$ statistics indicated significant levels of statistical heterogeneity across all analyses. However, publication bias was only evident in analyses that considered pooled clinical controls.

Overall Effect of Childhood Adversity in Studies Comparing BPD and Psychiatric Controls

A forest plot of the 61 case control studies comparing BPD to clinical controls, after the removal of outliers $(40,61,70-77)$, is presented in Figure 3. The analysis indicated that individuals with BPD are 3.36 times more likely to report childhood adversity compared to psychiatric controls (95\% CI 3.05-3.69, $p<.001)$. Meta-regression 
indicated that NOAS quality ratings did not predict the observed effects $(\beta=-.03, \mathrm{SE}=$ $.03, p=.322$ ). After the inclusion of ten potentially missing effects using the Trim and Fill method, the association between BPD and childhood adversity remained robust; $\mathrm{OR}=3.15(95 \% \mathrm{CI} 2.87-3.47, p<.001)$. The single epidemiological study indicated an effect of $\mathrm{OR}=3.12(95 \%$ CI $2.74-3.70, p<.001)$.

[INSERT TABLE 2 APPROXIMATELY HERE]

[INSERT FIGURE 3 APPROXIMATELY HERE]

Effect of Childhood Adversity in Studies Comparing BPD and Mood Disorders

We conducted analyses exploring levels of childhood adversity in BPD compared to mood disorders. After the removal of three outliers $(33,40,103)$, case control studies comparing levels of childhood adversity in BPD compared to mood disorder controls indicated a pooled effect of $\mathrm{OR}=3.06(95 \% \mathrm{CI} 2.54-3.80, p<.001)$. Therefore, BPD samples are approximately three times more likely to report childhood adversity than those with mood disorders. This effect was larger when BPD samples were compared to bipolar disorder $(\mathrm{k}=9, \mathrm{OR}=466,95 \% \mathrm{CI} 3.64-5.97, p<.001)$, rather than other mood disorder samples $(\mathrm{k}=15, \mathrm{OR}=2.86,95 \% \mathrm{CI} 2.21-3.714, p<.001)$.

Effect of Childhood Adversity in Studies Comparing BPD and Other Personality Disorders

After the removal of outliers $(59,71)$ childhood adversity in BPD and other personality disorder controls indicated a pooled effect of $\mathrm{OR}=2.84(95 \%$ CI $2.42-3.33$, 
$p<.001$ ), suggesting greater probability of reported childhood adversity in individuals with a diagnosis of BPD relative to individuals with other personality disorder diagnoses.

Effect of Childhood Adversity in Studies Comparing BPD and Psychosis

After the removal of one outlier (75), studies comparing childhood adversity in BPD and psychosis controls indicated a pooled effect of $\mathrm{OR}=3.43(95 \%$ CI $2.76-4.37$ $p<.001)$. There was no evidence of publication bias. This indicates that individuals with BPD are over three times more likely to report childhood adversity compared to individuals with psychosis. 


\section{Discussion}

This meta-analysis reviewed and synthesised data comparing levels of childhood adversity in individuals with BPD to non-clinical and clinical controls. Findings the available literature suggested a large association between childhood adversity and BPD. Additional analyses indicated that BPD was associated with elevated rates of all included subtypes of adversity, with particularly large effects when considering emotional abuse and neglect. When compared to clinical controls, our meta-analyses indicated that individuals with a diagnosis of BPD are more likely to report experiences of childhood adversity than other psychiatric groups, including patients with mood disorders, psychosis and other personality disorders.

The finding that individuals with a diagnosis of BPD were over thirteen times more likely to report childhood adversity than non-clinical controls is consistent with the strong clinical narrative linking childhood adversity and BPD (21). Furthermore, the relative large effects observed for emotional abuse and neglect are consistent with previous theoretical and empirical research suggesting links to emotional invalidation and rejection sensitivity (10, 121-122). Large discrepancies were found in the magnitude of the association between childhood adversity and BPD across investigations using different study designs.

Specifically, the synthesis of statistical findings extracted from case-control studies generally led to considerably larger summary effects than those observed in the small number of epidemiological and prospective cohort studies included in this review. Also noteworthy is that, when pooled, the overall effect size of the two prospective studies was non-significant $(p=.070)$, although each individual study showed a significant relationship with variation in the magnitude of the effect. This may have been due to performing random-effects metaanalysis with a small K, which increases the likelihood of Type I and Type II errors. Further 
prospective longitudinal research is therefore required to better understand the exact effect of child adversity on BPD.

The reasons for such marked differences in effect sizes across the literature cannot be identified with confidence at this stage, but could be due to multiple factors. First, it is possible that these discrepancies are due to higher risk of selection bias in case-control studies, which might lead to overestimations of adversity prevalence in BPD samples if, for example, individuals with more severe trauma histories are also more likely to come to the attention of clinical services, and consequently be recruited in clinical research studies. Furthermore, while case-control studies often employ participant selection procedures to ensure that BPD patients are compared to 'healthy controls' known to be free of other psychiatric diagnoses, in epidemiological studies the comparison of interest are members of the general population, where other psychiatric diagnoses linked to adversity exposure may be present. Similarly, in prospective studies, participants exposed to childhood adversity may develop mental health difficulties other than BPD. Lastly, the variation in effect sizes might have been due to differences in measurement, including the use of retrospective reporting and the psychometric properties of the employed assessments. Additional longitudinal and large epidemiological investigations are needed before clearer conclusion can be drawn regarding the above discrepancies, if replicated.

Our findings indicate that patients diagnosed with BPD are more likely report childhood adversity than those receiving other clinical diagnoses. This is somewhat surprising given the high rates of childhood adversity already identified in other clinical groups $(16-18,122,124)$. It is potentially explained by overlap between complex PTSD (CPTSD) and BPD criteria, which has led to proposals that BPD could also be conceptualised as a trauma-related disorder (125). Indeed, research has demonstrated comparable levels of sexual or physical abuse and neglect in individuals diagnosed with PTSD and BPD, but also 
particularly elevated rates of abuse and neglect when these disorders are comorbid (74). Given the recognition of the C-PTSD diagnosis for ICD-11 and the introduction of new diagnostic criteria for this clinical presentation (126), further research is urgently needed to clarify the relative overlap between these constructs. The potential impact of co-morbidity more broadly also requires careful consideration. Whilst the majority of eligible studies systematically confirmed the absence of BPD in controls, co-morbidity within the BPD sample was common. This is to be expected and may suggest ecological validity, given the high rates of comorbidity in individuals with BPD reported in other research (127-128). However, it is possible that findings reflect an increased rate of comorbidity associated within childhood abuse, rather than BPD per se.

\section{Limitations of the review}

This meta-analysis is not without limitation. Our focus on examining the impact of childhood adversity on clinical outcomes in adulthood is in line with previous reviews on other severe mental health difficulties (e.g. 17, 124), and allows for a more direct comparison between the meta-analytic findings observed in this review and those in other diagnostic groups. However, our approach could be criticised for not considering the evidence provided by case-control studies conducted on children and adolescents with BPD, which has been recently synthesised by others (23). As the literature on childhood adversity in BPD youth expands, future meta-analytic reviews could attempt to integrate these bodies of research and examine the impact of childhood adversities and BPD across the life span. Regarding our search strategy, although combining title and abstract searches is standard practice, using separate stages allows for the removal of clearly inappropriate and ineligible studies at an early stage. It is unclear which approach is more appropriate, but this is a possible limitation. 
Our analyses revealed high levels of statistical heterogeneity, likely due to high levels of clinical and methodological differences between studies. Although the majority of studies used similar diagnostic criteria, the varied clinical characteristics of the samples could have influenced the exact magnitude of the observed effects (e.g. hospitalisation status; acute or remitted status). Similarly, the measurement of childhood adversity varied considerably across studies, both in terms of the type (e.g. sexual abuse, physical abuse, emotional neglect) and assessment method (e.g. self-report questionnaires, semi structured interviews, court records). Additionally, a risk of publication bias was identified for the majority of analyses within this literature. This may be due to a strong narrative within research and clinical settings around the role played by childhood adversity in the development of BPD (21), which in turn could discourage the publication of evidence to the contrary. This limitation notwithstanding, the observed effects remained strong and significant after correcting for the presence of publication bias using the Trim and Fill method. Similarly, our analyses identified multiple potential 'outlier' studies presenting unusually large or small effects that might bias the results of certain analyses. In all cases, the analyses we conducted after removing suspected outliers led to summary effects that were comparable to those obtained in the analyses of all relevant studies (as indicated by large overlap in CIs), with the exception of the analysis comparing BPD to non-clinical controls on physical abuse, for which a difference in summary effects was more noticeable $(\mathrm{OR}=6.82,95 \% \mathrm{CI} 4.90-9.50$ and $\mathrm{OR}$ $=9.18,95 \%$ CI $7.07-11.93$, respectively). An additional limitation is that the different types of adversity were non-independent and, as a result, we cannot comment of the specificity of individual adversity effects. It is important to acknowledge that other forms of childhood adversity or genetic factors may also play a role in the development of BPD (129).

There were noteworthy methodological limitations of the primary studies included in this meta-analysis. The majority of studies used self-report, retrospective measures and only 
two studies corroborated accounts of adversity with official records. It has been suggested that retrospective measurement is susceptible to false memories and cognitive distortions (130). However, research has suggested that recall bias only explains a small amount of the variance in retrospective childhood adversity assessments (131) and that reporting of childhood abuse within personality disorder samples is largely consistent over time (132). The majority of studies failed to state whether assessors were blind to diagnosis, which may have biased adversity ratings.

\section{Research and Clinical Implications}

The findings of this review, in line with other meta-analytic evidence (23), indicate that trauma is highly prevalent in people with a diagnosis of BPD. However, carefully designed longitudinal research, including examination of dose-response relationships, is required before definitive conclusions can be drawn regarding any causal role played by childhood adversity in the development of BPD. Nevertheless, preventing childhood adversity represents a critical area for intervention and the routine assessment of abuse and neglect as part of standard health assessments has previously been advocated $(133,134)$. The findings support the importance of trauma informed care for individuals accessing mental health services and forensic settings, where prevalence rates of BPD are high (135).

To summarise, the findings of this review, which is based largely on cross sectional research, indicate a strong association between BPD and childhood adversity. This is consistent with the past theoretical literature $(10,21,136-137,138)$, but further research is needed to explore whether this represents a causal relationship and whether any effect is moderated by biological, social and psychological factors. Research exploring the relationships between childhood adversity and specific features of BPD may facilitate 
understanding of the current overlap or co-morbidity with other complex post-traumatic presentations. 


\section{References}

1. American Psychiatric Association. Diagnostic and statistical manual of mental disorders (4th ed., Text Revision). Washington DC, 2000

2. Loranger AW. International Personality Disorder Examination. Florida: Psychological Assessment Resources, 1999.

3. Gunderson JG. Borderline personality disorder: Ontogeny of a diagnosis. Am J Psychiatry. 2009: 166:530-9.

4. Holm AL, Severinsson E. The emotional pain and distress of borderline personality disorder: A review of the literature. Int J Ment Health Nurs. 2008:17:27-35.

5. Holm AL, Severinsson E. The emotional pain and distress of borderline personality disorder: A review of the literature. Int J Ment Health Nurs. 2008:17:27-35.

6. Moran P, Romaniuk H, Coff C, et al. The influence of personality disorder on the future mental health and social adjustment of young adults: a population-based, longitudinal cohort study. The Lancet Psychiatry. 2016: 3: 636-45.

7. Sansone R, Farukhi S, Wiederman M. Utilization of primary care physicians in borderline personality. Gen Hosp Psychiatry. 2011:33:343-6.

8. Dale O, Sethi F, Stanton C, et al. Personality disorder services in England: Findings from a national survey. BJPsych Bull. 2017:41:247-53.

9. Cristea IA, Gentili C, Cotet CD, et al. Efficacy of psychotherapies for borderline personality disorder: A systematic review and meta-analysis. JAMA. 2017:74:319-328.

10. Linehan MM. Cognitive-Behavioral Treatment of Borderline Personality Disorder. New York: The Guilford Press; 1993.

11. Bradley R, Westen, D. The psychodynamics of borderline personality disorder: A view from developmental psychopathology. Development and Psychopathology. 2005:17:927957.

12. Herzog JI, Schmahl C. Adverse childhood experiences and the consequences on neurobiological, psychosocial, and somatic conditions across the lifespan. Front Psychiatry. 2018:9:420.

13. Lui R, Scopelliti KM, Pittman SK, Zamora AS. Childhood maltreatment and nonsuicidal self-injury: A systematic review and meta-analysis. The Lancet Psychiatry. 2018:5:51-64.

14. Ford JD, Courtois CA. Complex PTSD, affect dysregulation, and borderline personality disorder. Borderline Personal Disord Emot Dysregulation. 2014:1:9. 
15. Herman J. Complex PTSD: A syndrome in survivors of prolonged and repeted trauma. J Trauma Stress. 1992:377-92.

16. Norman RE, Byambaa M, De R, et al. The Long-Term Health Consequences of Child Physical Abuse, Emotional Abuse, and Neglect: A Systematic Review and MetaAnalysis. PLoS Med. 2012:9.

17. Varese F, Smeets F, Drukker M, et al. Childhood adversities increase the risk of psychosis: A meta-analysis of patient-control, prospective-and cross-sectional cohort studies. Schizophr Bull. 2012:38:661-71.

18. Afifi TO, Mather A, Boman J, et al. Childhood adversity and personality disorders: Results from a nationally representative population-based study. J Psychiatr Res. 2011:45:814-22.

19. Ball JS, Links PS. Borderline personality disorder and childhood trauma: evidence for a causal relationship. Curr Psychiatry Rep. 2009:11:63-8.

20. Newnham EA, Janca A. Childhood adversity and borderline personality disorder: A focus on adolescence. Curr Opin Psychiatry. 2014:27:68-72.

21. Graybar SR, Boutilier LR. Nontraumatic pathways to borderline personality disorder. Psychother Theor Res Pract Train. 2002:39:152-162.

22. Stepp SD, Lazarus SA, Byrd AL. A systematic review of risk factors prospectively associated with borderline personality disorder: Taking stock and moving forward. Personal Disord Theory, Res Treat. 2016:7:316-23.

23. Winsper C, Lereya ST, Marwaha S, Thompson A, Eyden J, Singh SP. The aetiological and psychopathological validity of borderline personality disorder in youth: A systematic review and meta-analysis. Clin Psychol Rev. 2016:44:13-24.

24. Fossati A, Madeddu F, Maffei C. Borderline Personality Disorder and childhood sexual abuse: A meta-analytic study. J Pers Disord. 1999:13:104-139.

25. Wells G, Shea B, O'Connell D, et al. The Newcastle-Ottawa Scale (NOS) for Assessing the Quality of Nonrandomized Studies in Meta-Analysis. 2000.

26. Hunt M. Borderline personality disorder across the lifespan. J Women Aging. 2007:19:173-91.

27. Sansone RA, Sansone LA. Gender Patterns in Borderline Personality Disorder. Innov Clin Neurosci. 2011:8:16-20. 
28. Borenstein M, Hedges L, Higgins J, et al. Comprehensive Meta-Analasis. Eaglewood, NJ: Biostat; 2005.

29. Cuijpers P. Meta-analysis in Mental Health Research: A Practical Guide. Amsterdam: Vrije Universiteit Amsterdam: 2016.

30. Bandelow B, Krause J, Wedekind D, et al. Early traumatic life events, parental attitudes, family history, and birth risk factors in patients with borderline personality disorder and healthy controls. Psychiatry Res. 2005:134:169-79.

31. Barker V, Romaniuk L, Cardinal RN, et al. Impulsivity in borderline personality disorder. Psychological Medicine. 2015:45:1955-64.

32. Bungert M, Liebke L, Thome J, Haeussler K, Bohus M, Lis S. Rejection sensitivity and symptom severity in patients with borderline personality disorder: Effects of childhood maltreatment and self-esteem. Borderline Personality Disorder and Emotion Dysregulation. 2015:2:4.

33. Carvalho-Fernando S, Beblo T, Schlosser N, et al. The impact of self-reported childhood trauma on emotion regulation in borderline personality disorder and major depression. $\mathrm{J}$ Trauma Dissociation. 2014:15:384-401.

34. Chiesa M, Fonagy P. Reflective function as a mediator between childhood adversity, personality disorder and symptom distress. Personal Ment Health [Internet]. 2014:8:5266.

35. Krause-Utz A, Erol E, Brousianou AV, et al. Self-reported impulsivity in women with borderline personality disorder: The role of childhood maltreatment severity and emotion regulation difficulties. Borderline Personality Disorder and Emotion Dysregulation. 2019:6.

36. Laporte L, Paris J, Guttman H, et al. Using a Sibling Design to Compare Childhood Adversities in Female Patients with BPD and Their Sisters. Child Maltreat. 2012:17:31829.

37. Sar V, Akyuz G, Kugu N, et al. Axis I dissociative disorder comorbidity in borderline personality disorder and reports of childhood Diseases of the Nervous System: 2006:67:1583-90.

38. Schwarze CE, Hellhammer DH, Stroehle V, et al. Lack of breastfeeding: A potential risk factor in the multifactorial genesis of borderline personality disorder and impaired maternal bonding. J Pers Disord. 2015:29:610-26. 
39. Semiz U, Basoglu C, Cetin M, et al. Body dysmorphic disorder in patients with borderline personality disorder: Prevalence, clinical characteristics, and role of childhood trauma. Acta Neuropsychiatr. 2008;20:33-40.

40. Wingenfeld K, Schaffrath C, Rullkoetter N, et al. Associations of childhood trauma, trauma in adulthood and previous-year stress with psychopathology in patients with major depression and borderline personality disorder. Child Abus Negl. 2011:35:647-54.

41. Bichescu-Burian D, Steyer J, Steinert T, Grieb B, Tschoke S. Trauma-related dissociation: Psychological features and psychophysiological responses to script-driven imagery in borderline personality disorder. Psychophysiology. 2017:54:452-461.

42. Brakemeir E, Dobias J, Hertel J, et al. Childhood maltreatment in women with borderline personality disorder, chronic depression, and episodic depression, and in healthy controls. Psychother Psychosom. 2018:87:49-51.

43. Brune M, O J, Schojai M, et al. Mating strategies and experience of early adversity in female patients with borderline personality disorder: Insights from life history theory. Pers Individ Dif. 2017:113:147-154.

44. Catalan A, Angosto V, Diaz A, et al. Relation between psychotic symptoms, parental care and childhood trauma in severe mental disorders. Psychiatry Res. 2017:251:78-84.

45. Driessen M, Herrmann J, Stahl K, et al. Magnetic resonance imaging volumes of the hippocampus and the amygdala in women with borderline personality disorder and early traumatization. Arch Gen Psychiatry. 2000:57:1115-22.

46. Duque-Alarcon X, Alcala-Lozano R, Gonzalez-Olvera JJ, et al. Effects of childhood maltreatment on social cognition and brain functional connectivity in borderline personality disorder patients. Front Psychiatry. 2019:10.

47. Ebert A, Kolb M, Heller J, et al. Modulation of interpersonal trust in borderline personality disorder by intranasal oxytocin and childhood trauma. Soc Neurosci. 2013:8:305-13.

48. Ernst M, Mohr HM, Schott M, et al. The effect of social exclusion on response inhibition in borderline personality disorder and major depression. Psychiat Res. 2018:262:333339.

49. Figueroa EF, Silk KR, Huth A,et al. History of childhood sexual abuse and general psychopathology. Compr Psychiatry. 1997:38:23-30. 
50. Flasbeck V, Enzi B, Brüne M. Childhood trauma affects processing of social interactions in borderline personality disorder: An event-related potential study investigating empathy for pain. World J Biol Psychiatry. 2017:5:1-11.

51. Giesen-Bloo J, Arntz A. World assumptions and the role of trauma in borderline personality disorder. J Behav Ther Exp Psychiatry. 2005:36:197-208.

52. Jin, X, Zhong, M, Yao, S, et al. A voxel-based morphometric MRI study in young adults with borderline personality disorder. PLoS ONE: 2016:11.

53. Kaiser D, Jacob GA, van Zutphen L, et al. Patients with borderline personality disorder and comorbid PTSD show biased attention for threat in the facial dot-probe task. J Behav Ther Exp Psychiatry. 2018.

54. Kim M-K, Kim J-S, Park H-I, et al. Early life stress, resilience and emotional dysregulation in major depressive disorder with comorbid borderline personality disorder. J Affect Disord. 2018:236:113-119.

55. Kuhlmann A, Bertsch K, Schmidinger I, et al. Morphometric differences in central stress-regulating structures between women with and without borderline personality disorder. J Psychiatry Neurosci. 2013:28:129-137.

56. Kulacaoglu F, Solmaz M, Ardic FC, et al. The relationship between childhood traumas, dissociation, and impulsivity in patients with borderline personality disorder comorbid with ADHD. Pcychiat Clin Psych. 2017:27:393-402.

57. Laporte L, Guttman H. Abusive relationships in families of women with borderline personality disorder, anorexia nervosa and a control group. J Nerv Ment Dis [Internet]. 2001:189:522-31.

58. Lee RJ, Hempel J, TenHarmsel A, et al. The neuroendocrinology of childhood trauma in personality disorder. Psychoneuroendocrinology. 2012:37:78-86.

59. Lobbestael J, Arntz A, Sieswerda S. Schema modes and childhood abuse in borderline and antisocial personality disorders. Spec Issue Cogn Emot Borderline Personal Disord. 2005:36:240-53.

60. Mazer AK, Cleare AJ, Young AH, et al. Bipolar affective disorder and borderline personality disorder: Differentiation based on the history of early life stress and psychoneuroendocrine measures. Behav Brain Res. 2019:357-358:48-56.

61. Merza K, Papp G, Szabo IK. The role of childhood traumatization in the development of borderline personality disorder in Hungary. Eur J Psychiatry [Internet]. 2015:29:105-18. 
62. Pietrek C, Elbert T, Weierstall R, et al. Childhood adversities in relation to psychiatric disorders. Psychiatry Res. 2013:206:103-10.

63. Popkirov S, Flasbeck V, Schlegel U, et al. Childhood trauma and dissociative symptoms predict frontal EEG asymmetry in borderline personality disorder. J Trauma Dissociation. 2018:20:32-47.

64. Richard-Lepouriel H, Kung A-L, Hasler R, et al. Impulsivity and its association with childhood trauma experiences across bipolar disorder, attention deficit hyperactivity disorder and borderline personality disorder. J Affect Disord. 2019:244:33-41.

65. Simeon D, Nelson D, Elias R, et al. Relationship of Personality to Dissociation and Childhood Trauma in Borderline Personality Disorder. CNS Spectr. 2003:8:755-62.

66. Steiger H, Leonard S, Ng Ying Kin N, et al. Childhood abuse and platelet tritiatedparoxetine binding in bulimia nervosa: Implications of borderline personality disorder. $\mathrm{J}$ Clin Psychiatry. 2000:61:428-35.

67. Thomsen MS, Ruocco AC, Carcone D, et al. Neurocognitive deficits in borderline personality disorder: Associations with childhood trauma and dimensions of personality psychopathology. J Pers Disord. 2017:31:503-521.

68. van Heel M, Luyten P, De Meulemeester C, et al. Mentalizing based on external features in borderline personality disorder compared with healthy controls: The role of attachment dimensions and childhood trauma. J Pers Disord. 2019:33:1-15.

69. van Zutphen L, Siep N, Jacob GA, et al. Always on guard: Emotion regulation in women with borderline personality disorder compared to nonpatient controls and patients with cluster-C personality disorder. J Psychiatry Neurosci. 2018:43:37-47.

70. Bornovalova MA, Gratz KL, Delany-Brumsey A, et al. Temperamental and environmental risk factors for borderline personality disorder among inner-city substance users in residential treatment. J Pers Disord. 2006:20:218-31.

71. Frias A, Palma C, Farriols N, et al. Anxious adult attachment may mediate the relationship between childhood emotional abuse and borderline personality disorder. Personal Ment Health. 2016:10:274-84.

72. Gratz KL, Tull MT, Baruch DE, et al. Factors associated with co-occurring borderline personality disorder among inner-city substance users: The roles of childhood maltreatment, negative affect intensity/reactivity, and emotion dysregulation. Compr Psychiatry. 2008:49:603-15. 
73. Joyce PR, McKenzie JM, Luty SE, et al. Temperament, childhood environment and psychopathology as risk factors for avoidant and borderline personality disorders. Aust $\mathrm{N}$ Z J Psychiatry. 2003:37:756-64.

74. Pagura J, Stein MB, Bolton JM, et al. Comorbidity of borderline personality disorder and posttraumatic stress disorder in the U.S. population. J Psychiatr Res. 2010:44:1190-8.

75. Tschoeke S, Steinert T, Flammer E, et al. Similarities and differences in borderline personality disorder and schizophrenia with voice hearing. J Nerv Ment Dis [Internet]. 2014:202:544-9.

76. van Dijke A, Ford JD, van der Hart O, et al. Childhood traumatization by primary caretaker and affect dysregulation in patients with borderline personality disorder and somatoform disorder. Eur J Psychotraumatol. 2011:2:5628.

77. Zlotnick C, Johnson DM, Yen S, et al. Clinical features and impairment in women with borderline personality disorder (BPD) with posttraumatic stress disorder (PTSD), BPD without PTSD, and other personality disorders with PTSD. J Nerv Ment Dis. 2003:191:706-714.

78. Battle CL, Shea MT, Johnson DM, et al. Childhood maltreatment associated with adult personality disorders: Findings from the collaborative longitudinal personality disorders study. J Pers Disord. 2004:18:193-211.

79. Bayes A, Graham RK, Parker GB, et al. Is 'subthreshold' bipolar II disorder more difficult to differentiate from borderline personality disorder than formal bipolar II disorder? Psychiat Res. 2018:264:416-420.

80. Bayes AJ, McClure G, Fletcher K, et al. Differentiating the bipolar disorders from borderline personality disorder. Acta Psychiatr Scand. 2016:133:187-95.

81. Boen E, Hummelen B, Elvsashagen T, et al. Different impulsivity profiles in borderline personality disorder and bipolar II disorder. J Affect Disord. 2014:170:104-11.

82. Brodsky BS, Oquendo M, Ellis SP, et al. The relationship of childhood abuse to impulsivity and suicidal behavior in adults with major depression. Am J Psychiatry. 2001:158:1871-7.

83. Brown GR, Anderson B. Psychiatric morbidity in adult inpatients with childhood histories of sexual and physical abuse. Am J Psychiatry. 1991:148:55-61.

84. Byrne CP, Velamoor VR, Cernovsky ZZ, et al. A comparison of borderline and schizophrenic patients for childhood life events and parent-child relationships. Can J Psychiatry. 1990:35:590-5. 
85. Chesin M, Fertuck E, Goodman J, et al. The interaction between rejection sensitivity and emotional maltreatment in borderline personality disorder. Psychopathology.

2015:48:31-5.

86. Chiesa M, Larsen-Paya M, Martino M, et al. The relationship between childhood adversity, psychiatric disorder and clinical severity: Results from a multi-centre study. Psychoanal Psychother. 2016:30:79-95.

87. Dittrich K, Boedeker K, Klucznoik D, et al. Child abuse potential in mothers with early life maltreatment, borderline personality disorder and depression. Br J Psychiatry. 2018:213:412-418.

88. Ducasse D, Lopez-Castroman J, Dassa D, et al. Exploring the boundaries between borderline personality disorder and suicidal behavior disorder. Eur Arch Psychiatry Clin Neurosci. 2019.

89. Ferrer M, Andion O, Calvo N, et al. Differences in the association between childhood trauma history and borderline personality disorder or attention deficit/hyperactivity disorder diagnoses in adulthood. Eur Arch Psychiatry Clin Neurosci. 2016:1-9.

90. Goldberg JF, Garno JL. Age at onset of bipolar disorder and risk for comorbid borderline personality disorder. Bipolar Disord. 2009:11:205-8.

91. Golier JA, Yehuda R, Bierer LM, et al. The Relationship of Borderline Personality Disorder to Posttraumatic Stress Disorder and Traumatic Events. Am J Psychiatry. 2003:160:2018-24.

92. Herman JL, Perry JC, Van der Kolk BA. Childhood trauma in borderline personality disorder. Am J Psychiatry. 1989:146:490-5.

93. Hernandez A, Arntz A, Gaviria AM, et al. Relationships between childhood maltreatment, parenting style, and borderline personality disorder criteria. J Pers Disord. 2012:26:727-36.

94. Huang J, Yang Y, Wu J, et al. Childhood abuse Chinese patients with borderline personality disorder. J Pers Disord. 2012:26:238-54.

95. Kingdon DG, Ashcroft K, Bhandari B, et al. Schizophrenia and borderline personality disorder: Similarities and differences in the experience of auditory hallucinations, paranoia, and childhood trauma. J Nerv Ment Dis. 2010:198:399-403.

96. Machizawa-Summers S. Childhood trauma and parental bonding among Japanese female patients with borderline personality disorder. Int J Psychol. 2007;42:265-73. 
97. McDermid J, Sareen J, El-Gabalawy R, et al. Co-morbidity of bipolar disorder and borderline personality disorder: findings from the National Epidemiologic Survey on Alcohol and Related Conditions. Compr Psychiatry. 2015:58:18-28.

98. Nickel MK, Tritt K, Mitterlehner FO, et al. Sexual abuse in childhood and youth as psychopathologically relevant life occurrence: Cross-sectional survey. Croat Med J. 2004:45:483-9.

99. Ogata SN, Silk KR, Goodrich S, et al. Childhood sexual and physical abuse in adult patients with borderline personality disorder. American Journal of Psychiatry: 1990:147:1008-13.

100. Paris J, Zweig-Frank H, Guzder J. Psychological risk factors for borderline personality disorder in female patients. Compr Psychiatry. 1994:35:301-5.

101. Paris J, Zweig-Frank H, Guzder J. Risk factors for borderline personality in male outpatients. Journal of Nervous and Mental Disease: 1994:182:375-80.. US: Lippincott Williams \& Wilkins; 1994. p. 375-80.

102. Park LC, Imboden JB, Park TJ, et al. Giftedness and psychological abuse in borderline personality disorder: Their relevance to genesis and treatment. J Pers Disord. 1992:6:226-40.

103. Perroud N, Zewdie S, Stenz L, et al. Methylation of serotonin receptor 3A in ADHD, borderline personality, and bipolar disorders: Link with severity of the disorder and childhood maltreatment. Depress Anxiety. 2016:33:45-55.

104. Roberts A, Yang M, Zhang T, et al. Personality disorder, temperament, and childhood adversity: Findings from a cohort of prisoners in England and Wales. J Forens Psychiatry Psychol. 2008:19:460-83.

105. Sansone RA, Songer DA, Miller KA. Childhood abuse, mental healthcare utilization, self-harm behavior, and multiple psychiatric diagnoses among inpatients with and without a borderline diagnosis. Compr Psychiatry. 2005:46:117-20.

106. Soderberg S, Kullgren G, Renberg ES, et al. Childhood sexual abuse predicts poor outcome seven years after parasuicide. Social Psychiatry and Psychiatric Epidemiology: 2004: 39:916-20.

107. Steiger H, Jabalpurwala S, Champagne J. Axis II Comorbidity and Developmental Adversity in Bulimia Nervosa. J Nerv Ment Dis. 1996:184:555-60. 
108. Wapp M, van de Glind G, van Emmerik-van Oortmerssen K, et al. Risk factors for borderline personality disorder in treatment seeking patients with a substance use disorder: An international multicenter study. Eur Addict Res. 2015:21:188-94.

109. Weaver TL, Clum GA. Early family environments and traumatic experiences assocaited with borderline personality disorder. J Consult Clin Psych. 1993:61:10681075.

110. Weibel S, Vidal S, Olie E, et al. Impact of child maltreatment on meaning in life in psychiatric patients. Psychiatry Res. 2017:251:204-11.

111. Goodman M, Weiss DS, Koenigsberg H, et al. The Role of Childhood Trauma in Differences in Affective Instability in Those With Personality Disorders. CNS Spectr. 2003:8:763-70.

112. Williams R, Holliday R, Clem M, et al. Borderline personality disorder and military sexual trauma: Analysis of previous traumatization and current psychiatric presentation. $\mathrm{J}$ Interpers Violence. 2017:37:2223-2236.

113. Wilson ST, Stanley BH, Brent DA, et al. Interaction between tryptophan hydroxylase I polymorphisms and childhood abuse is associated with increased risk for borderline personality disorder in adulthood. Psychiatr Genet. 2012:22:15-24.

114. Wonderlich SA, Swift WJ. Borderline versus other personality disorders in the eating disorders: Clinical description. Int J Eat Disord. 1990:9:629-38.

115. Wong H-M, Leung HC-M, Chow L-Y. Prevalence of borderline personality disorder and its clinical correlates in Chinese patients with recent deliberate self-harm. J Pers Disord. 2010:24:800-11.

116. Wota AP, Byrne C, Murray I, et al. An examination of childhood trauma in individuals attending an adult mental health service. Ir J Psychol Med. 2014:31:259-70.

117. Zanarini MC, Gunderson JG, Marino MF, et al. Childhood experiences of borderline patients. Compr Psychiatry . 1989:30:18-25.

118. Zanarini MC, Frankenburg FR. Pathways to the development of borderline personality disorder. Spec Issue Trauma Personal Disord. 1997:11:93-104.

119. Zhang TH, Chow A, Wang LL, et al. Childhood maltreatment profile in a clinical population in China: A further analysis with existing data of an epidemiologic survey. : 2013:54:856-64. 
120. Zlotnick C, Mattia J, Zimmerman M. Clinical features of survivors of sexual abuse with major depression. Child Abus Negl. 2001:25:357-67.

121. Robertson CD, Kimbrel NA, Nelson-Gray RO. The Invalidating Childhood Environment Scale (ICES): Psychometric Properties and Relationship to Borderline Personality Symptomatology. J Pers Disord. 2013:27:402-10.

122. Nelson J, Klumparendt A, Doebler P, et al. Childhood maltreatment and characteristics of adult depression: Meta-analysis. Br J Psychiatry. 2017:210:96-104.

123. Foxhall M, Hamilton-Giachritsis C, Button K. The link between rejection sensitivity and borderline personality disorder: A systematic review and meta-analysis. British Journal of Clinical Psychology. 2019:58:289-326.

124. Palmier-Claus JE, Berry K, Bucci S, et al. Relationship between childhood adversity and bipolar affective disorder: Systematic review and meta-analysis. Br J Psychiatry. 2016:209:454-9.

125. Ford JD, Courtois CA. Complex PTSD, affect dysregulation, and borderline personality disorder. Borderline Personal Disord Emot Dysregulation. 2014:1:9.

126. Karatzias T, Cloitre M, Maercker A, et al. PTSD and Complex PTSD : ICD-11 updates on concept and measurement in. Eur J Psychotraumatol. 2018:8

127. Grilo CM, Sanislow CA, McGlashan TH. Co-occurence of DSM-IV personality disorders with borderline personality disorder. J Nerv Ment Dis. 2002:190:552-4.

128. Zanarini MC, Frankenburg FR, Dubo ED, et al. Axis I Comorbidity of Borderline Personality Disorder Borderline patients often present for evaluation or. Am J PsychiatryAm J Psychiatry. 1998: 155:12:1733-9.

129. Nia AB, Eveleth MC, Gabbay JM, et al. Past, present, and future of genetic research in borderline personality disorder. Curr Opin Psychol. 2018:21:60-8.

130. Paris J. Memories of abuse in borderline patients: true or false?. Harv Rev Psychiatry. 1995:31:10-7.

131. Fergusson DM, Horwood J, Boden JM. Structural equation modeling of repeated retrospective reports of childhood maltreatment. Int J Methods Psychiatr Res. 2011:20 :93-104. 
132. Spinhoven P, Bamelis L, Haringsma R, et al. Consistency of reporting sexual and physical abuse during psychological treatment of personality disorder: An explorative study. J Behav Ther Exp Psychiatry. 2012:43:43-50.

133. Read J, Hammersley P, Rudegeair T. Why, when and how to ask about childhood abuse. Adv Psychiatr Treat. 2007:13:101-10.

134. Sampson M, Read J. Are mental health staff getting better at asking about abuse and neglect? Int J Ment Health Nurs. 2017:26:95-104.

135. Black DW, Gunter T, Allen J, et al. Borderline personality disorder in male and female offenders newly committed to prison. Compr Psychiatry. 2007:48:400-5.

136. Bradley R, Jenei J, Westen D. Etiology of Borderline Personality Disorder: Disentangling the Contributions of Intercorrelated Antecedents.2005:193:24-31.

137. Herman J. Complex PTSD: A syndrome in survivors of prolonged and repeted trauma. J Trauma Stress. 19955:377-92.

138. Cattane N, Rossi R, Lanfredi M, Cattaneo A. Borderline personality disorder and childhood trauma: Exploring the affected biological systems and mechanisms. BMC Psychiatry. 2017:17:1-14.

139. Nicol K, Pope M, Romaniuk L, et al. Childhood trauma, midbrain activation and psychotic symptoms in borderline personality disorder. Transl Psychiatry. 2015:5:e559.

140. Schwarze CE, Mobascher A, Pallasch B, et al. Prenatal adversity: A risk factor in borderline personality disorder? Psychol Med. 2013:1279-1291. 


\section{TABLES}

Table 1. All Random Effect Meta-analyses of Studies Comparing BPD to Non Clinical Control groups

Adversity Type
OR (95\% Confidence Interval) Heterogeneity Tests

Eggers test

k OR Lower Upper p

$\mathrm{I}^{2}$

$Q \quad$ df $\quad p$

\section{Case Control Studies}

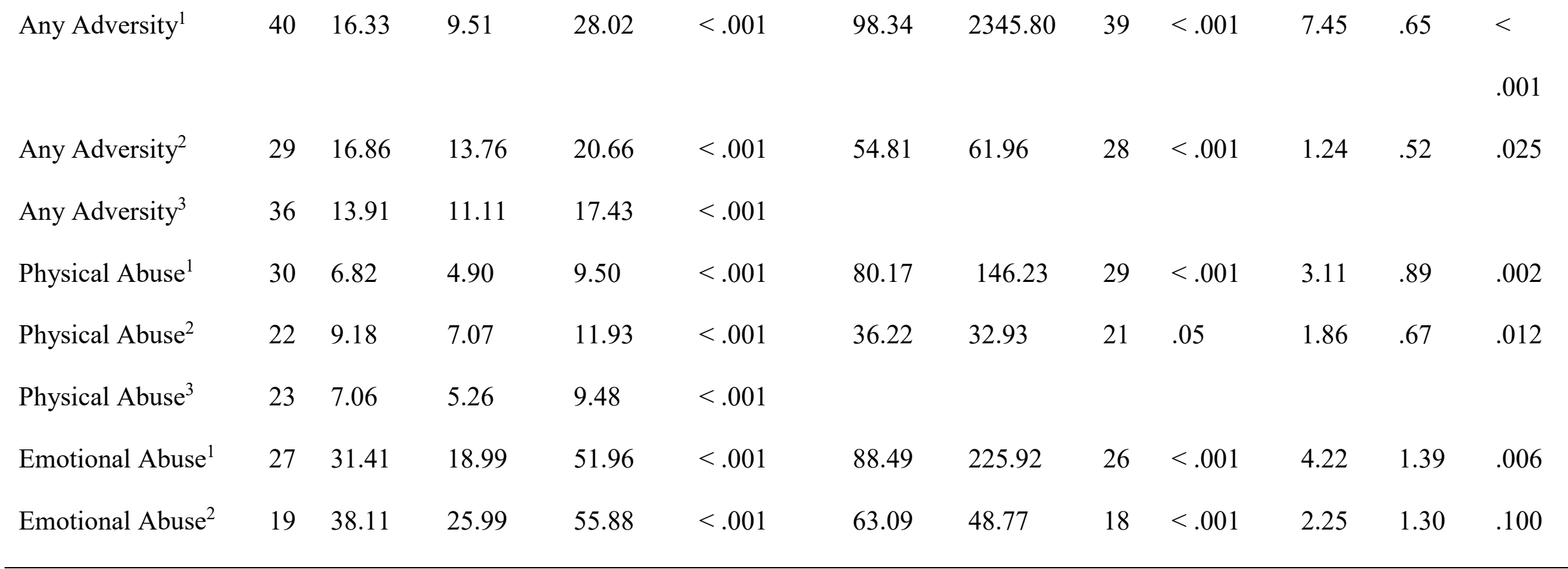




\begin{tabular}{|c|c|c|c|c|c|c|c|c|c|c|c|c|}
\hline \multirow[t]{2}{*}{ Adversity Type } & & \multicolumn{4}{|c|}{ OR (95\% Confidence Interval) } & \multicolumn{4}{|c|}{ Heterogeneity Tests } & \multicolumn{3}{|c|}{ Eggers test } \\
\hline & $\mathrm{k}$ & OR & Lower & Upper & $\mathrm{p}$ & $\mathrm{I}^{2}$ & $Q$ & $\mathrm{df}$ & $p$ & $\beta$ & $\mathrm{SE}$ & $\mathrm{p}$ \\
\hline Sexual Abuse ${ }^{1}$ & 33 & 6.60 & 5.15 & 8.47 & $<.001$ & 63.51 & 87.69 & 32 & $<.001$ & 2.19 & .69 & .003 \\
\hline Sexual Abuse $^{2}$ & 30 & 6.76 & 5.41 & 8.44 & $<.001$ & 48.84 & 56.68 & 29 & .002 & 1.74 & .62 & .009 \\
\hline Sexual Abuse ${ }^{3}$ & 35 & 5.96 & 4.72 & 7.52 & $<.001$ & & & & & & & \\
\hline Physical Neglect $^{1}$ & 21 & 7.97 & 5.21 & 12.19 & $<.001$ & 79.87 & 99.34 & 20 & $<.001$ & 1.28 & 1.22 & .306 \\
\hline Physical Neglect ${ }^{2}$ & 15 & 7.61 & 5.74 & 10.11 & $<.001$ & 27.97 & 19.44 & 14 & .149 & 1.24 & .62 & .064 \\
\hline Physical Neglect ${ }^{3}$ & 19 & 6.93 & 5.23 & 9.20 & $<.001$ & & & & & & & \\
\hline Emotional Neglect ${ }^{1}$ & 26 & 22.97 & 15.02 & 35.15 & $<.001$ & 83.95 & 155.81 & 25 & $<.001$ & 2.93 & 1.33 & .037 \\
\hline Emotional Neglect ${ }^{2}$ & 19 & 23.06 & 17.21 & 30.90 & $<.001$ & 48.73 & 35.11 & 18 & .009 & 2.06 & .81 & .022 \\
\hline Emotional Neglect ${ }^{3}$ & 25 & 17.73 & 13.01 & 24.17 & $<.001$ & & & & & & & \\
\hline \multicolumn{13}{|c|}{ Epidemiology Studies } \\
\hline Any Adveristy ${ }^{1}$ & 2 & 2.56 & 1.24 & 5.30 & .011 & 59.87 & 2.49 & 1 & .114 & & & \\
\hline Physical Abuse $^{1}$ & 1 & 2.40 & 1.70 & 2.45 & $<.001$ & & & & & & & \\
\hline Emotional Abuse $^{1}$ & 1 & 2.31 & 1.87 & 2.86 & $<.001$ & & & & & & & \\
\hline Sexual Abuse $^{1}$ & 1 & 2.47 & 1.42 & 2.97 & $<.001$ & & & & & & & \\
\hline
\end{tabular}




\begin{tabular}{|c|c|c|c|c|c|c|c|c|c|c|c|c|}
\hline \multirow[t]{2}{*}{ Adversity Type } & & \multicolumn{4}{|c|}{ OR (95\% Confidence Interval) } & \multicolumn{4}{|c|}{ Heterogeneity Tests } & \multicolumn{3}{|c|}{ Eggers test } \\
\hline & $\mathrm{k}$ & OR & Lower & Upper & $\mathrm{p}$ & $\mathrm{I}^{2}$ & $Q$ & $\mathrm{df}$ & $p$ & $\beta$ & SE & $\mathrm{p}$ \\
\hline \multicolumn{13}{|c|}{ Prospective Cohort studies } \\
\hline Any Abuse ${ }^{1}$ & 2 & 2.59 & .93 & 7.30 & .070 & 76.08 & 4.18 & 1 & .041 & & & \\
\hline Physical Abuse $^{1}$ & 1 & 2.09 & 1.71 & 2.44 & $<.001$ & & & & & & & \\
\hline Emotional Abuse $^{1}$ & 1 & 4.99 & 1.83 & 13.55 & .002 & & & & & & & \\
\hline Sexual Abuse ${ }^{1}$ & 1 & 1.46 & .67 & 3.18 & .340 & & & & & & & \\
\hline
\end{tabular}


TABLE 2 All Meta-analyses Results for BPD vs Clinical Control Studies

\begin{tabular}{|c|c|c|c|c|c|c|c|c|c|c|c|c|}
\hline \multirow[t]{2}{*}{ Control } & \multicolumn{5}{|c|}{ OR (95\% Confidence Interval) } & \multicolumn{4}{|c|}{ Heterogeneity Tests } & \multicolumn{3}{|c|}{ Eggers test } \\
\hline & $\mathrm{k}$ & OR & Lower & Upper & $p$ & $\mathrm{I}^{2}$ & $Q$ & $\mathrm{df}$ & $p$ & $\beta$ & $\mathrm{SE}$ & $p$ \\
\hline Mixed Psychiatric $^{1}$ & 71 & 3.30 & 2.61 & 3.76 & $<.001$ & 95.07 & 1420.63 & 70 & $<.001$ & 3.92 & .41 & $<.001$ \\
\hline Mixed Psychiatric ${ }^{2}$ & 61 & 3.36 & 3.05 & 3.69 & $<.001$ & 49.20 & 118.10 & 60 & $<.001$ & .71 & .30 & .023 \\
\hline Mixed Psychiatric ${ }^{3}$ & 71 & 3.15 & 2.87 & 3.47 & $<.001$ & & & & & & & \\
\hline Personality Disorders ${ }^{1}$ & 19 & 2.60 & 2.14 & 3.16 & $<.001$ & 73.56 & 68.07 & 18 & $<.001$ & .42 & .83 & .623 \\
\hline Personality Disorders ${ }^{2}$ & 17 & 2.84 & 2.42 & 3.33 & $<.001$ & 53.00 & 34.05 & 16 & .005 & .66 & .63 & .313 \\
\hline Mood Disorders ${ }^{1}$ & 24 & 3.42 & 2.77 & 4.23 & $<.001$ & 69.13 & 74.51 & 23 & $<.001$ & .63 & .87 & .477 \\
\hline Mood Disorders ${ }^{2}$ & 21 & 3.65 & 3.12 & 4.27 & $<.001$ & 30.93 & 28.96 & 20 & $<.001$ & .01 & .61 & .985 \\
\hline Psychosis $^{1}$ & 6 & 3.97 & 2.53 & 6.24 & $<.001$ & 69.64 & 16.47 & 5 & .006 & 1.80 & 2.19 & .456 \\
\hline Psychosis $^{2}$ & 5 & 3.43 & 2.66 & 4.42 & $<.001$ & 13.97 & 4.65 & 4 & .325 & 2.12 & 1.66 & .291 \\
\hline
\end{tabular}

141. Mixed Psychiatric control (MPC), Other Personality Disorder Control (OPD), Mood Disorder Control (OPD), Psychosis Control (PSY).

142. ${ }^{1}$ Analysis of all eligible studies, ${ }^{2}$ Analysis of all eligible studies, outliers removed, ${ }^{3}$ Analysis of all eligible studies with outliers removed and trim and fill correction for potential publication or selection bias. $\mathrm{k}$ denotes all imputed and observed studies in the trim and fill analysis. 


\section{FIGURES}

Figure 1. Flow Chart of Eligibility Screen
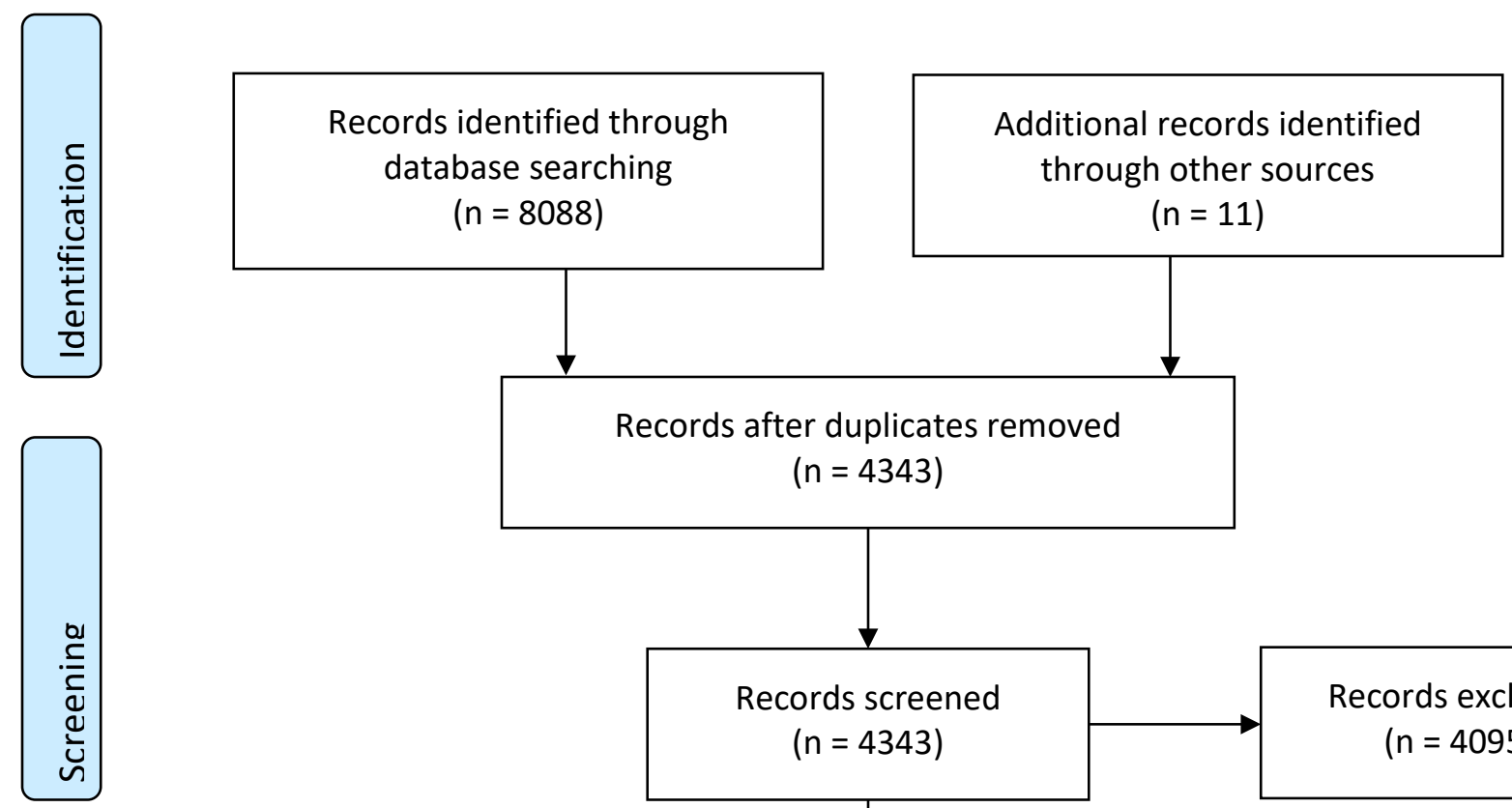

Records after duplicates removed
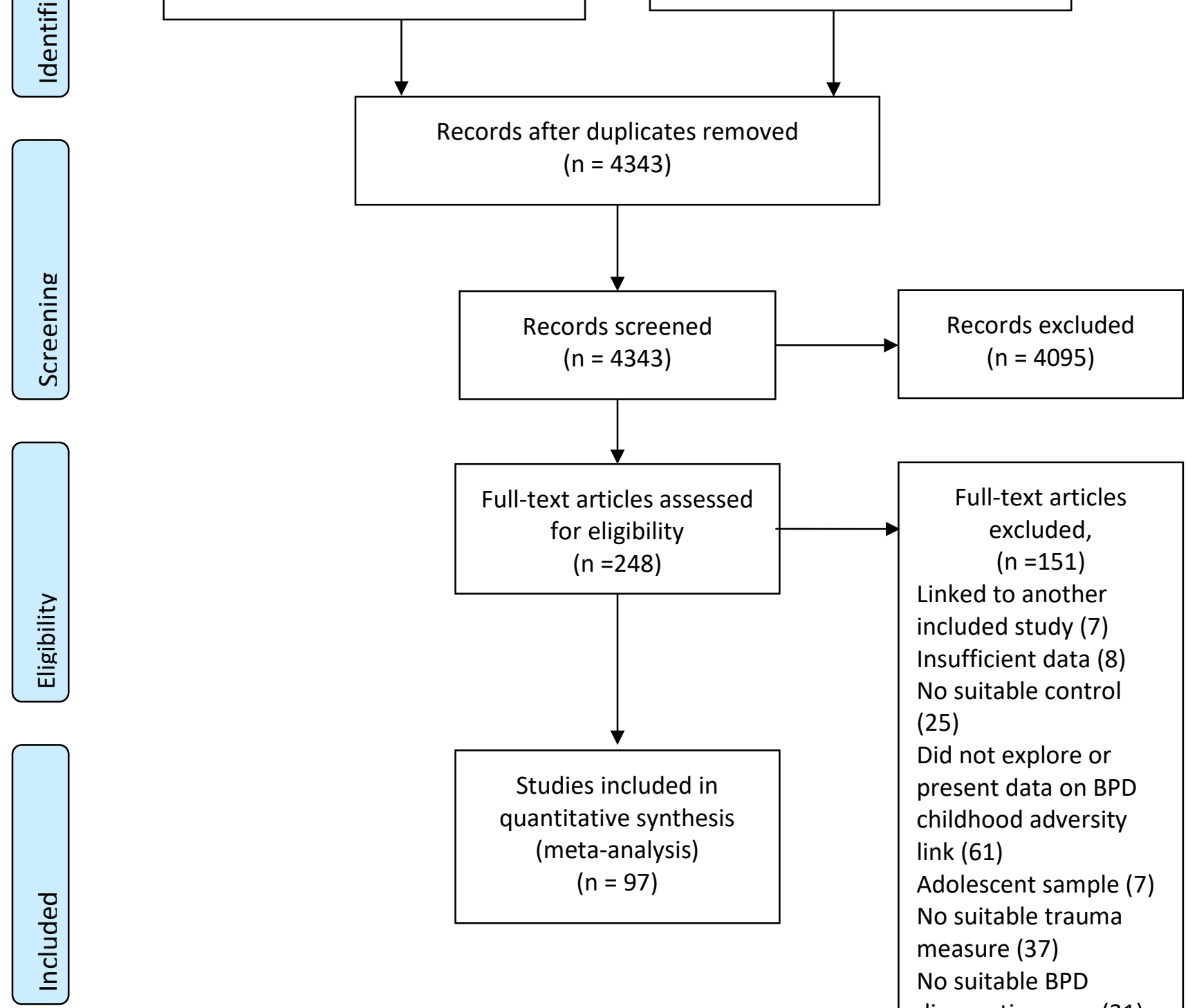

\begin{tabular}{|l|}
$\begin{array}{c}\text { Full-text articles } \\
\text { excluded, } \\
(\mathrm{n}=151)\end{array}$ \\
$\begin{array}{l}\text { Linked to another } \\
\text { included study (7) } \\
\text { Insufficient data (8) } \\
\text { No suitable control } \\
(25) \\
\text { Did not explore or } \\
\text { present data on BPD } \\
\text { childhood adversity } \\
\text { link (61) } \\
\text { Adolescent sample (7) } \\
\text { No suitable trauma } \\
\text { measure (37) } \\
\text { No suitable BPD } \\
\text { diagnostic group (31) }\end{array}$ \\
\hline
\end{tabular}




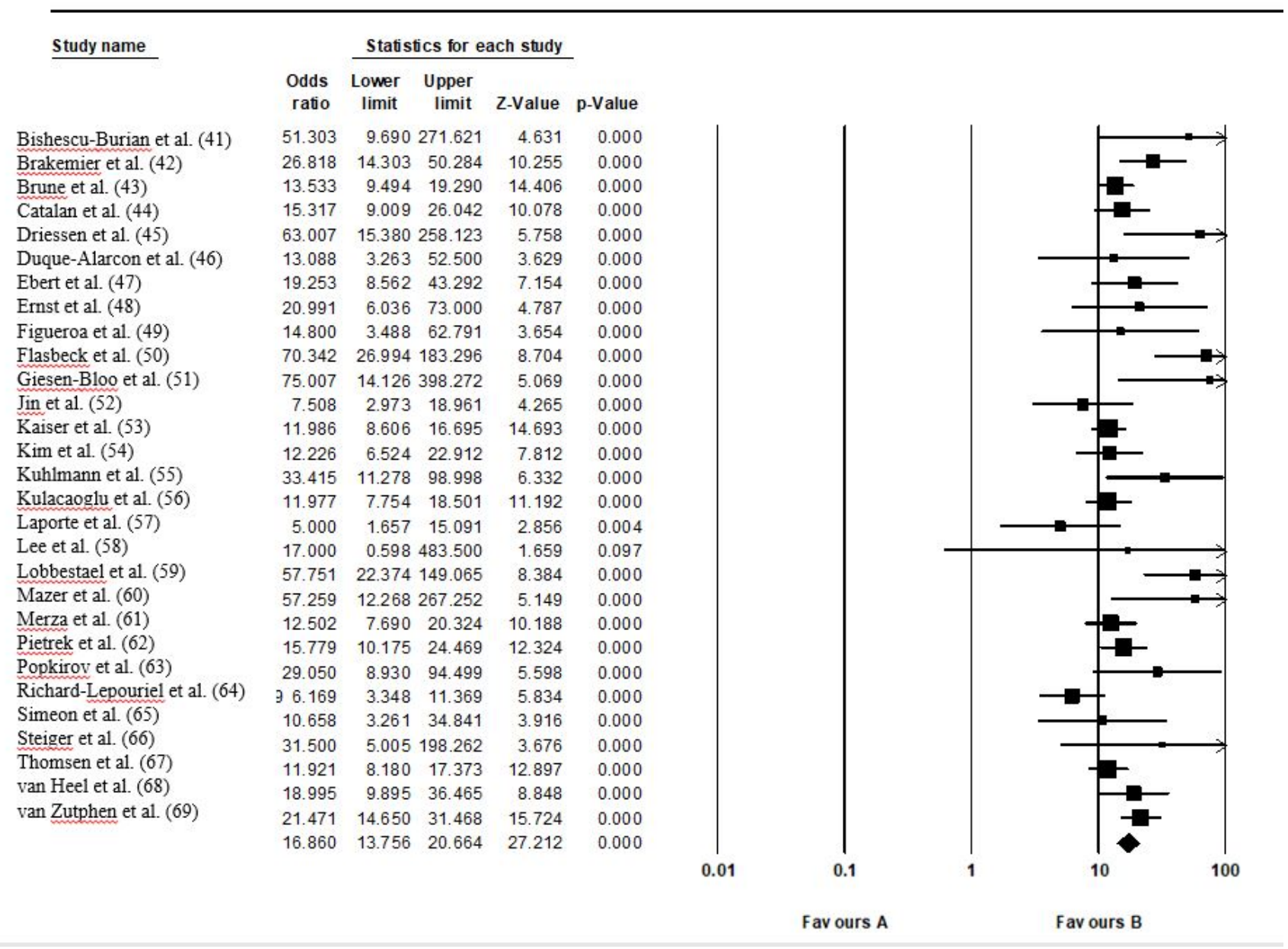

Figure 2. Forest plot with individual effect sizes for case control studies comparing BPD to non-clinical controls for any adversity with outliers removed. 


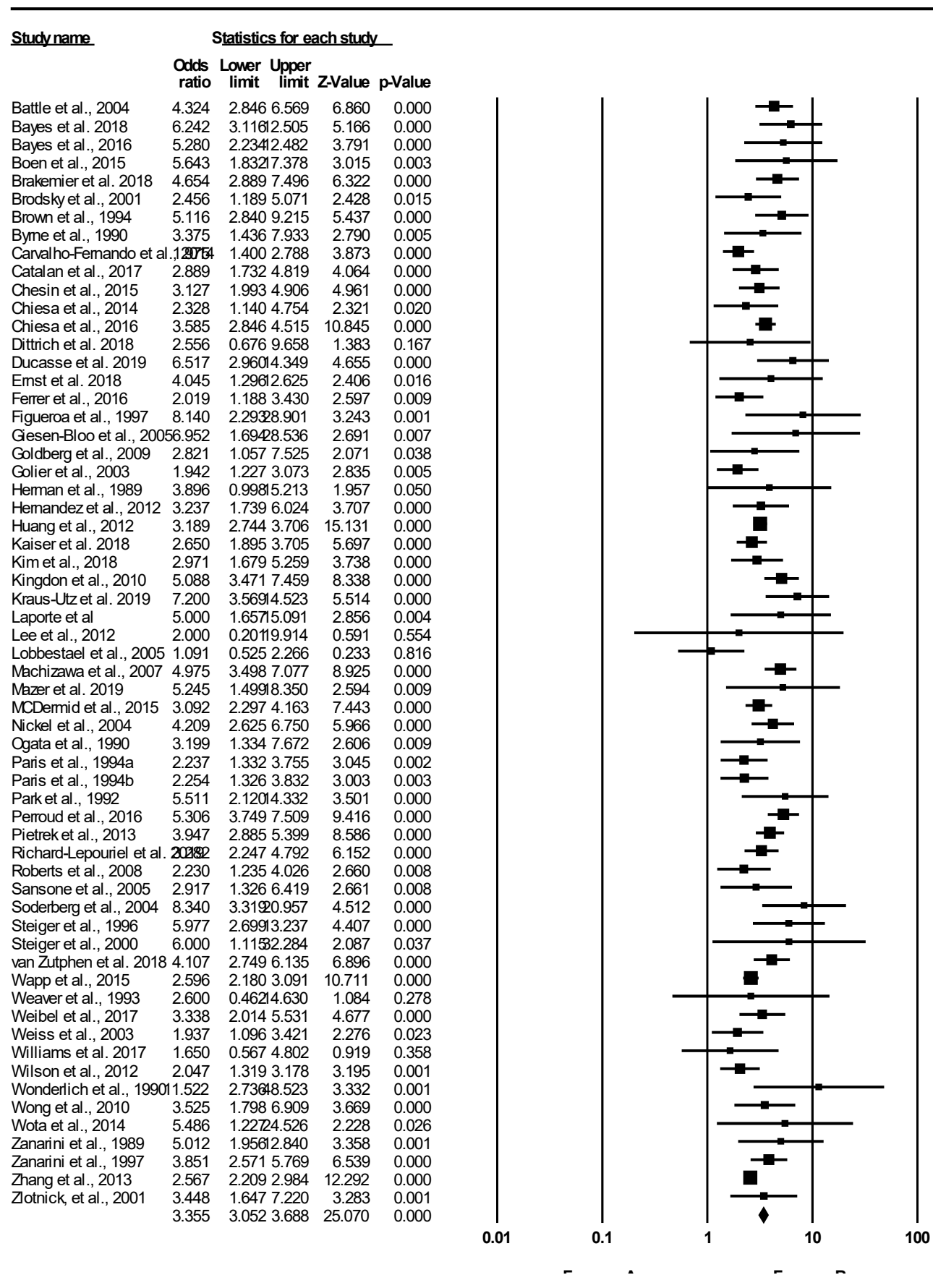

Figure 3. Forest Plot and individual effect sizes for each case control study comparing BPD

to a clinical control group, with outliers removed. 